\title{
The cumulative carbon budget and its implications
}

\section{Richard Millar,* Myles Allen,** Joeri Rogelj,*** and Pierre Friedlingstein****}

\begin{abstract}
The cumulative impact of carbon dioxide $\left(\mathrm{CO}_{2}\right)$ emissions on climate has potentially profound economic and policy implications. It implies that the long-term climate change mitigation challenge should be reframed as a stock problem, while the overwhelming majority of climate policies continue to focus on the flow of $\mathrm{CO}_{2}$ into the atmosphere in 2030 or 2050 . An obstacle, however, to the use of a cumulative carbon budget in policy is uncertainty in the size of this budget consistent with any specific temperature-based goal such as limiting warming to $2^{\circ} \mathrm{C}$. This arises from uncertainty in the climate response to $\mathrm{CO}_{2}$ emissions, which is relatively tractable, and uncertainty in future warming due to non- $\mathrm{CO}_{2}$ drivers, which is less so. We argue these uncertainties are best addressed through policies that recognize the need to reduce net global $\mathrm{CO}_{2}$ emissions to zero to stabilize global temperatures but adapt automatically to evolving climate change. Adaptive policies would fit well within the Paris Agreement under the UN Framework Convention on Climate Change.
\end{abstract}

Keywords: climate change, climate policy, fossil fuels, uncertainty, integrated assessment, carbon budgets

JEL classification: Q540, Q580, Q350

*Department of Physics, University of Oxford, e-mail: richard.millar@physics.ox.ac.uk

**School of Geography and the Environment, University of Oxford, e-mail: myles.allen@ouce.ox.ac.uk

*** International Institute for Applied Systems Analysis, e-mail: rogelj@iiasa.ac.at ****University of Exeter, e-mail: p.friedlingstein@exeter.ac.uk

\section{Introduction}

Climate change, and its associated economic impact, is one of the most significant pressures that human society is placing on the natural environment (Rockström et al., 2009). Since pre-industrial times, temperatures have risen by about $0.9^{\circ} \mathrm{C}$ across the globe, with nearly every location across the globe experiencing warming (Stocker et al., 2013; Otto et al., 2015). This change is overwhelmingly driven by human activity, primarily by emissions of carbon dioxide $\left(\mathrm{CO}_{2}\right)$ released from the combustion of fossil fuels for energy, with nearly all of the observed warming being directly attributable to human activity (Bindoff et al., 2013). Observed and projected future warming, in which temperatures could increase to almost $5^{\circ} \mathrm{C}$ warmer than preindustrial times by the end of the century (Collins et al., 2013), is very likely to have large economic impacts, including stresses on water availability, crop-production, and increased damages from extreme weather events, to name only a few (Field et al., 2014).

Mitigating and ultimately halting future climate change also proposes a profound economic and policy challenge, particularly in light of the recent Paris Agreement of the UN Framework Convention on Climate Change (UNFCCC) to: 
hold the increase in global average temperature to well below $2{ }^{\circ} \mathrm{C}$ above pre-industrial levels and to pursue efforts to limit the temperature increase to $1.5^{\circ} \mathrm{C}$ above pre-industrial levels, recognizing that this would significantly reduce the risks and impacts of climate change. (UNFCCC, 2015)

Scientific insights over the last several years have shown that it is the cumulative $\mathrm{CO}_{2}$ emissions (sum total of all emissions over time) that primarily determine peak (maximum) human-induced warming. The cumulative nature of the impact of $\mathrm{CO}_{2}$ emissions on the climate follows inescapably from the longevity of fossil carbon released into the so-called 'active' carbon cycle of the atmosphere, biosphere, and upper ocean (Archer, 2005; Archer and Brovkin, 2008). A single pulse of carbon released into the atmosphere at any point in time rapidly increases temperatures by a fixed amount, with temperatures remaining approximately constant for several centuries thereafter (Matthews and Caldeira, 2008). Therefore, temperatures in any given year are largely determined by cumulative $\mathrm{CO}_{2}$ emissions up to that time (Allen et al., 2009; Matthews et al., 2009; Zickfield et al., 2009) and temperatures do not decline for many centuries even after a complete cessation of $\mathrm{CO}_{2}$ emissions (Solomon et al., 2009). It is therefore necessary to reduce global net emissions of $\mathrm{CO}_{2}$ to zero in order to stop the planet warming.

An important, and simplifying, corollary is that once emissions are reduced to zero, relatively little further warming occurs in the majority of scenarios, at least over the ensuing century or so. It is important to distinguish between stabilizing atmospheric concentrations (which would allow substantial further warming as temperatures come into equilibrium: see the discussion of equilibrium and transient responses in section III), and stabilizing cumulative carbon emissions (i.e. reducing the net flow of emissions to zero), which stabilizes temperatures because subsequent thermal adjustment is approximately balanced by subsequent ocean uptake of atmospheric $\mathrm{CO}_{2}$ (Solomon et al., 2009).

These scientific insights offer a powerful framework to analyse climate policy, and has formed the basis of the 'carbon budget' approach that has become more prevalent in economic and financial analyses of carbon mitigation (e.g. the Carbon Tracker Initiative, 2011) and have been used by many as justification in calling for a large fraction of fossil fuels to be left in the ground (350.org, 2012; McGlade and Ekins, 2015).

The 5th Assessment Report of the Intergovernmental Panel on Climate Change (IPCC) provides the latest assessment of evidence on the climatic effect of cumulative $\mathrm{CO}_{2}$ emissions ${ }^{1}$ as follows: 'Cumulative emissions of $\mathrm{CO}_{2}$ largely determine global mean surface warming by the late twenty-first century and beyond' (Stocker et al., 2013; Pachauri et al., 2014). On the actual size of the cumulative carbon budget to limit warming to less than $2^{\circ} \mathrm{C}$, the IPCC is rather less succinct, stating in the Synthesis Report (Pachauri et al., 2014):

\footnotetext{
${ }^{1}$ The IPCC gave updated carbon budgets based largely on Gillett et al. (2013), which took account of updated estimates of the strength of anthropogenic forcing and the evolution of global temperatures since 2000 .
} 
Multi-model results show that limiting total human-induced warming to less than $2^{\circ} \mathrm{C}$ relative to the period $1861-1880$ with a probability of $>66 \%$ would require cumulative $\mathrm{CO}_{2}$ emissions from all anthropogenic sources since 1870 to remain below about 2,900 $\mathrm{GtCO}_{2}$ [billion tonnes of $\mathrm{CO}_{2}$ ] (with a range of 2,550-3,150 $\mathrm{GtCO}_{2}$ depending on non- $\mathrm{CO}_{2}$ drivers). About $1,900 \mathrm{GtCO}_{2}$ had already been emitted by 2011.'

Given in the unit ${ }^{2} \mathrm{GtC}$, the $>66$ per cent probability budget becomes $790 \mathrm{GtC}$, with a remaining budget in 2011 of $275 \mathrm{GtC}$ after subtracting the $515 \mathrm{GtC}$ historical emissions.

Many analyses have typically summarized the above by focusing on a remaining carbon budget of $1,000 \mathrm{GtCO}_{2}(790 \mathrm{GtC})$, corresponding to an estimated $>66$ per cent chance of limiting warming to less than $2^{\circ} \mathrm{C}$, of 'allowable emissions' from 2011 onwards, largely consistent with numbers originally published in Meinshausen et al. (2009). It is important to acknowledge that beneath this simple and useful figure there are a number of assumptions regarding the probability of different magnitudes of climate response and the future evolution of drivers of climate change other than $\mathrm{CO}_{2}$. This trillion tonne budget conceals a more complex picture regarding allowable future emissions and levels of certainty over the peak warming outcome (e.g. Friedlingstein et al., 2014; Rogelj et al., in press), which we intend to explore in this article.

Focusing initially on uncertainty in the climate response to $\mathrm{CO}_{2}$, the IPCC Working Group 1 report on Physical Climate Science (Stocker et al., 2013), makes a more specific statement about uncertainty in $\mathrm{CO}_{2}$-induced warming, which is attributable directly to uncertainty in the climate response to $\mathrm{CO}_{2}$ emissions (slightly edited here for clarity):

Limiting the warming caused by anthropogenic $\mathrm{CO}_{2}$ emissions alone with a probability of $>33 \%,>50 \%$, and $>66 \%$ to less than $2{ }^{\circ} \mathrm{C}$ since the period 1861-1880 will require cumulative $\mathrm{CO}_{2}$ emissions from all anthropogenic sources to stay [below] about $5,760 \mathrm{GtCO}_{2}(1570 \mathrm{GtC}), \ldots$ 4,440 $\mathrm{GtCO}_{2}$ $(1,210 \mathrm{GtC})$, and . . 3,670 $\mathrm{GtCO}_{2}(1,000 \mathrm{GtC})$ since that period respectively.

Accounting for historical emissions these budgets would be reduced to 1,055 GtC, $695 \mathrm{GtC}$, and $485 \mathrm{GtC}$ in 2011, respectively. This uncertainty, attributable to the physical response to cumulative emissions alone, clearly creates a wide range of future cumulative emissions that could be consistent with meeting the same $2^{\circ} \mathrm{C}$ goal. Formulating efficient mitigation policies under this uncertainty can be a difficult task.

Along with uncertainty over the physical climate response, cumulative $\mathrm{CO}_{2}$ emissions budgets for limiting overall human-induced warming to less than $2^{\circ} \mathrm{C}$ require additional assumptions about the contribution of non- $\mathrm{CO}_{2}$ warming to peak warming. Assuming that non- $\mathrm{CO}_{2}$ climate drivers contribute about $0.5^{\circ} \mathrm{C}$ to peak warming, as they do in most of scenarios considered by the IPCC, the remaining cumulative emissions budget for $\mathrm{CO}_{2}$ to limit total warming to less than $2^{\circ} \mathrm{C}$ with $>66$ per cent probability reduces by almost 45 per cent. However, future assumptions for non- $\mathrm{CO}_{2}$

\footnotetext{
${ }^{2} 1 \mathrm{GtC}=3.66 \mathrm{GtCO}_{2}$
} 
warming are by no means certain (Rogelj et al., 2015a) and therefore choosing a fraction of warming to reserve for non- $\mathrm{CO}_{2}$ warming poses a very difficult policy challenge.

These uncertainties pose challenging, but not insurmountable, obstacles for the efficient use of the carbon budget concept in designing economically optimal climate mitigation polices. These issues are often masked behind the use of a single number in policy analyses. This article aims to explore the economic relevance of the carbon budget approach, as well as to elicit the policy implications of the relevant uncertainties associated with it. Section II offers a primer on the physical mechanisms underpinning cumulative $\mathrm{CO}_{2}$ budgets and why the sensitivity of the climate to cumulative emissions is the most policy-relevant measure of the climate response. Section III extends this analysis to consider the impact of forms of uncertainty in the physical climate system on carbon budgets. We also here propose that the transient response to cumulative emissions (TCRE) would be a much better metric of physical climate response for use in integrated assessment models (IAMs), rather than the equilibrium climate sensitivity (ECS) that is currently most commonly used to sample physical uncertainty. Section IV then addresses some of the many policy-relevant questions over assumptions about the role of non- $\mathrm{CO}_{2}$ climate drivers in setting carbon budgets. One way of dealing with these endemic uncertainties in the remaining carbon budget is to note that if we wish to limit warming to $2^{\circ} \mathrm{C}$, irrespective of what happens to other climate drivers, net global $\mathrm{CO}_{2}$ emissions will need to be zero by the time total human-induced warming reaches $2^{\circ} \mathrm{C}$. ${ }^{3}$ Section $\mathrm{V}$ proposes a new way to frame climate mitigation policies as adaptive to the emergent climate response by indexing them to the evolving human-induced warming. The paper then finishes with a few concluding thoughts on the implications of these ideas for climate mitigation economics in section VI.

\section{The importance of cumulative carbon emissions to the climate system}

In this section, we illustrate the origins and importance of the cumulative carbon budget, using the database of emission scenarios compiled by the IPCC Working Group 3 (WG3) Report on Mitigation of Climate Change (Edenhofer et al., 2014; Clarke et al., 2014). ${ }^{4}$

Figure 1(a) illustrates the relationship between atmospheric $\mathrm{CO}_{2}$ concentrations and cumulative $\mathrm{CO}_{2}$ emissions under a broad range of scenarios of future emissions out to 2100. Atmospheric concentrations are computed in the WG3 database with a simple coupled carbon-cycle-climate model (a simplified representation of the interaction between the carbon-cycle and the climate system in a globally averaged sense; see Meinshausen et al. (2011) for details), calibrated against the more complex Earth System Models (3-dimensional models that solve the equations of the atmosphere, ocean, and carbon-cycle at points on a grid across the globe) used in the IPCC

\footnotetext{
${ }^{3}$ If temperatures are to be stabilized at that level without active geo-engineering (such as solar radiation management) and without temporarily allowing temperatures to exceed the $2^{\circ} \mathrm{C}$ limit. The latter would still require net zero global $\mathrm{CO}_{2}$ emissions at a later point in time, and the active net removal of $\mathrm{CO}_{2}$ from the atmosphere by human activities beyond the uptake of natural sinks thereafter.

${ }^{4}$ Available at https://secure.iiasa.ac.at/web-apps/ene/AR5DB/
} 
Assessments. We use a single set of parameters for our simple model that have been calibrated to the median response of the Earth System Models (Rogelj et al., 2012), allowing this figure to focus on the impact of scenario choice, and not on uncertainty in the climate response. The database contains a broad range of scenarios, including 'baseline' cases in which emissions continue unabated, with cumulative carbon emissions continuing past 3,000 $\mathrm{GtC}$ and atmospheric concentrations rising past 1,000 $\mathrm{ppm}^{5}$ by 2100 , as well as aggressive mitigation scenarios in which trajectories double back on themselves as cumulative emissions, and atmospheric $\mathrm{CO}_{2}$ concentrations are drawn down by substantial negative $\mathrm{CO}_{2}$ emissions. ${ }^{6}$

The blue dashed lines on the figure show various levels of 'cumulative airborne fraction', or CAF, the increase in atmospheric $\mathrm{CO}_{2}$ content as a fraction of total emitted $\mathrm{CO}_{2}$ (1 ppm in the atmosphere being equivalent to $\left.2.12 \mathrm{GtC}\right)$. The convex relationship between atmospheric $\mathrm{CO}_{2}$ concentrations and cumulative emissions in the simple model's response to the IPCC WG3 scenarios is very clear, indicating an increasing airborne fraction over time as emissions accumulate, leading to $\mathrm{CO}_{2}$ concentrations in 2100 that are up to $200 \mathrm{ppm}$ higher than they would be if the cumulative airborne fraction were to remain constant at its current level of around 0.4. This increase in airborne fraction between the twentieth and twenty-first century is a consistent feature of comprehensive climate-carbon-cycle models and results from the reduction in the rate of carbon-uptake by oceanic and terrestrial carbon sinks as atmospheric $\mathrm{CO}_{2}$ increases, and from the weakening (and in some models reversal) of $\mathrm{CO}_{2}$ uptake by oceanic and terrestrial sinks due to warming of the climate system (Friedlingstein et al., 2006; Ciais et al., 2013). A positive trend in airborne fraction has been observed (Raupach et al., 2008) but its origins and significance remain in dispute because of uncertainty in historical $\mathrm{CO}_{2}$ emissions, particularly from land-use change (Knorr, 2009; Gloor et al., 2010).

The convex shape of Figure 1 $(a)$ is important because some idealized simple carboncycle-climate models used in IAMs (e.g. Nordhaus and Sztorc, 2013), the evaluation of climate metrics (e.g. Boucher and Reddy, 2008; Myhre et al., 2013), or in calculating the social cost of carbon (e.g. Marten, 2011) use a representation of the carbon-cycle that gives a linear or even slightly concave relationship between atmospheric $\mathrm{CO}_{2}$ concentrations and cumulative $\mathrm{CO}_{2}$ emissions, with airborne fraction either constant or slightly decreasing as emissions accumulate over time. For example, the model and parameters used in Myhre et al. (2013) over-predicts $\mathrm{CO}_{2}$ concentrations to date if run under historical emissions, and under-predicts the increase for possible future emissions trajectories, relative to a model that allows for changing airborne fraction with cumulative emissions. A changing airborne fraction can be incorporated in a model by including a temperature-dependent carbon source (Tol, 2009) or a scaling on the rate of $\mathrm{CO}_{2}$ uptake (Hope, 2013) and is an essential feature to correctly represent the dependence of irreversible $\mathrm{CO}_{2}$-induced temperature

\footnotetext{
${ }^{5}$ IPCC estimates total fossil carbon reserves in 2011, economically recoverable with present-day technologies and prices, to be 1,000-2,000 GtC, in addition to the $515 \mathrm{GtC}$ already released and ongoing emissions due to land-use change, with corresponding potentially recoverable resources estimated at 8,500-14,000 GtC (Meinshausen et al., 2009; Bruckner et al., 2014; McGlade and Ekins, 2015). Hence there is not thought to be any significant resource limit on cumulative carbon emissions in the baseline scenarios for the remainder of this century (Scott et al., 2015).

${ }^{6}$ These are achieved, in the IAMs used to generate these scenarios, by the combination of large-scale biomass energy with carbon capture and sequestration. Whether this is feasible at the scale envisaged, given other constraints on land and water availability, is open to dispute (Kriegler et al., 2013).
} 
change on cumulative emissions.

Figure 1(b) shows $\mathrm{CO}_{2}$-induced warming in the IPCC WG3 scenarios plotted against atmospheric $\mathrm{CO}_{2}$ concentrations, again using the median climate response of the Earth System Model ensemble. In contrast to Figure 1(a), the figure shows a concave relationship, arising from the logarithmic relationship between atmospheric $\mathrm{CO}_{2}$ concentrations and the resulting 'radiative forcing', or perturbation on the planetary energy budget (meaning the ability of an increase in atmospheric concentration of a gas to trap energy within the climate system). Note that the temperatures plotted here are contemporaneous, those that emerge at the time concentrations reach the level shown in these scenarios, not some hypothetical long-term equilibrium temperature that might emerge were atmospheric concentrations to be stabilized indefinitely at these levels.

The dashed lines in Figure 1(b) show several values of the 'Transient Climate Response', or TCR. The TCR is a measure of the immediate warming induced by an increase in atmospheric $\mathrm{CO}_{2}$ concentrations (i.e. not specifically defined as a response to emissions of $\mathrm{CO}_{2}$ ) expected at the time $\mathrm{CO}_{2}$ concentrations reach a given level, before the system is allowed to re-equilibrate. TCR is formally defined as the warming at the time of $\mathrm{CO}_{2}$ doubling following a 1 per cent/year increase in $\mathrm{CO}_{2}$ concentrations over 70 years from initial equilibrium. Since the responses to radiative forcing are additive in most models of the climate system on these timescales, it can be used more generally to characterize the warming at the time $\mathrm{CO}_{2}$ concentrations reach any concentration following an approximately exponential increase. For any given TCR, warming increases logarithmically with $\mathrm{CO}_{2}$ concentration. The red curves depart from our simple model's TCR of $1.75^{\circ} \mathrm{C}$ because these scenarios are very different from a simple 70-year exponential, but, interestingly, not by very much. TCR therefore provides a reasonably accurate measure of $\mathrm{CO}_{2}$-induced warming in response to any radiative forcing varying over decadal timescales.

Figure 1(c) links the response in surface temperature (y-axis) to cumulative emissions (x-axis), using the relationships between atmospheric concentrations and cumulative emissions and concentrations and surface warming shown in Figures $1(a)$ and 1(b), respectively. When we plot $\mathrm{CO}_{2}$-induced warming against contemporaneous cumulative $\mathrm{CO}_{2}$ emissions (Figure $1(c)$ ), still using a single median estimate of climate system response, we see all scenarios falling on to almost exactly the same near-straight line. Remarkably, the relationship between $\mathrm{CO}_{2}$-induced warming and net cumulative carbon emissions is very similar in both baseline scenarios, in which emissions continue to rise throughout the twenty-first century, and aggressive mitigation scenarios, in which emissions are rapidly reduced and become strongly negative by the end of the century. Once cumulative emissions are specified, the rate of emission at any given time, even if it becomes negative, is immaterial to the resulting warming. Again, the grey line shows that failing to account for the increase in airborne fraction with cumulative emissions, as shown in Figure 1(a), results in an incorrect (concave) relationship between cumulative $\mathrm{CO}_{2}$ emissions and the resultant warming.

The slope of the red lines in Figure $1(c)$, or the ratio of $\mathrm{CO}_{2}$-induced warming observed by a given date (in units of ${ }^{\circ} \mathrm{C}$ ) to net cumulative $\mathrm{CO}_{2}$ emissions up to that date (in units of trillions of tonnes of carbon, or 1,000 GtC) is called the 'transient 
climate response to cumulative carbon emissions', or TCRE (Gillett et al., 2013). As Figure 1 $(c)$ shows, TCRE provides a scenario-independent metric of the climate system response to any $\mathrm{CO}_{2}$ emissions scenario in which emissions vary smoothly over multi-decadal timescales. The TCRE, as the slope of the straight line in Figure $1(c)$, is the most directly policy-relevant metric of the climate response to $\mathrm{CO}_{2}$ emissions, linking cumulative $\mathrm{CO}_{2}$ emissions with the resulting warming of the surface climate system.

Finally, Figure $1(d)$ shows total human-induced warming (including non- $\mathrm{CO}_{2}$ forcing specified by the scenario) plotted against cumulative $\mathrm{CO}_{2}$ emissions in the WG3 scenario database, again computed using a single median estimate of the climate response. The impact of future non- $\mathrm{CO}_{2}$ climate drivers introduces a somewhat greater spread, particularly between stringent mitigation scenarios, but the overall linear relationship between total human-induced warming and cumulative $\mathrm{CO}_{2}$ emissions remains clear. The pink plume in this figure shows the spread of responses of complex coupled Earth System Models (Knutti and Rogelj, 2015) to a specific baseline scenario (RCP8.5; Riahi et al., 2011), expressed as a 5-95 per cent range.

Figure 2 shows identical panels to Figure 1(a) and 1(b), demonstrating that the simple representation of the carbon-cycle-climate system used here is indicative of the relationship between these quantities in comprehensive Earth System Models. The coloured lines show the multi-model average response of the models in the CMIP5 Earth System Model inter-comparison project (Taylor et al., 2012) to four future emissions scenarios chosen to span the possible range of future radiative forcing on the climate system, known as the representative concentration pathways, or RCPs (van Vuuren et al., 2011). The shaded bands show the inter-model spread, expressed as a 5-95 per cent interval. Although these figures are based on full three-dimensional models, incorporating a vastly greater range of feedbacks and climate system components than the simple model used in Figure 1, and these plots show total human-induced warming and not simply $\mathrm{CO}_{2}$-induced warming, the essential features are the same, for the same physical and biogeochemical reasons: a convex relationship in panel $(a)$, and a compensating concave relationship in panel $(b)$. The linearity between cumulative emissions before a certain date and the temperature at that date is a well-established, well-understood, and fundamental feature of the climate system's response to $\mathrm{CO}_{2}$ emissions, best summarized by the TCRE.

To re-emphasize the point that cumulative emissions over all time are the best predictor of $\mathrm{CO}_{2}$-induced warming, as opposed to the flow of emissions in any given year, Figure 3 shows peak $\mathrm{CO}_{2}$-induced warming (or, in the case of temperatures failing to peak by then, warming in 2100) in the IPCC WG3 scenarios plotted against emission rates in 2030 and 2050 in Figure 3(a). Although 2050 emissions provide more information than 2030 emissions, neither emission rate provides a consistent guide to long-term warming. Figure $3(b)$ shows the same temperatures plotted against cumulative $\mathrm{CO}_{2}$ emissions to 2050 (e.g. McGlade and Ekins, 2015) and 2100. It shows that the carbon budget to 2050 is not as effective a predictor of peak warming or warming by 2100 as the carbon budget to 2100 , because the 2050 budget fails to take into account remaining emissions (or negative emissions) after 2050 that play a crucial role in determining subsequent warming in both baseline and mitigation scenarios. 


\section{Economically important climate system properties}

The TCRE, the slope of the lines in Figure 1(c), is arguably the most fundamentally important property of the climate system for mitigation policy, but is currently not directly used to assess physical climate response uncertainty sampling in most IAM models. The TCRE was assessed by the IPCC to be likely (>66 per cent) between 0.8 and $2.5^{\circ} \mathrm{C}$ per $1,000 \mathrm{GtC}$ for cumulative emissions up to about 2,000 GtC (Stocker et al., 2013). This uncertainty arises from uncertainty in the physical response of the climate system alone. In this section, we consider what determines the value of the TCRE and the origins of this uncertainty.

TCRE is equal (Matthews et al., 2009; Gillett et al., 2013) to the product of the CAF at the time of $\mathrm{CO}_{2}$ doubling multiplied by a factor of 2.12 (to convert units of $\mathrm{GtC}$ to the unit of concentrations, parts per million, or $\mathrm{ppm}$ ) and the TCR. Therefore, the uncertainty in the TCRE can be decomposed into the uncertainty in the response of the carbon cycle to a unit of cumulative emissions (the CAF) and the uncertainty in warming response of the climate system in response to a unit of radiative forcing (TCR). Most of the uncertainty in TCRE arises from uncertainty in TCR (Gillett et al., 2013), which represents the magnitude of the response of the climate system to an increasing radiative forcing: the IPCC gave a likely range for TCR of between 1 and $2.5^{\circ} \mathrm{C}$, only slightly lower than the corresponding uncertainty range on TCRE.

The equilibrium climate sensitivity (ECS) is defined as the long-term equilibrium warming resulting from an indefinitely sustained doubling of atmospheric $\mathrm{CO}_{2}$ concentrations. Despite being widely used as a variable parameter to sample climate response uncertainty, ECS is not directly related to TCRE and hence much less important than the TCR in determining the warming response to baseline and mitigation scenarios shown in Figures $1(c)$ and $1(d)$. We digress briefly here to explain why ECS is much less important to these scenarios, because it still remains widely and erroneously perceived to be the most policy-relevant parameter.

ECS and TCR are related, meaning models with a high ECS tend to have a high TCR and vice versa, complicating a discussion of which parameter is more important. It is simpler, therefore, to talk in terms of the TCR and the ratio of TCR to ECS, called the realized warming fraction, or RWF, ${ }^{7}$ which varies more independently of TCR (Millar et al., 2015) and therefore serves as a better additional parameter of the response to radiative forcing. Both peak warming under temperature-stabilization scenarios, for which forcing has to peak and decline, and the social cost of carbon under all but near-zero discount rates, are largely insensitive to RWF (Frame et al., 2006; Otto et $a l ., 2013)$. Hence once TCR is specified, the value of ECS is irrelevant to most policy decisions, but not vice versa.

This is illustrated by Figure 4, which shows the response of a simple, two-timeconstant response-to-radiative-forcing model of Myhre et al. (2013), which also provides the representation of the global temperature response to radiative forcing in the DICE2013R model (Nordhaus and Sztorc, 2013), to the $\mathrm{CO}_{2}$ concentrations

\footnotetext{
${ }^{7} \mathrm{RWF}=\mathrm{TCR} / \mathrm{ECS}$.
} 
shown in Figures $1(a)$ and 1(b). Figure 4(a) uses a constant value of TCR of $1.75^{\circ} \mathrm{C}$, while Figure $4(b)$ uses a constant value of ECS of $3.0^{\circ} \mathrm{C}$, in both cases varying the ratio between them (Millar et al., 2015). Colours represent different values of the RWF (the ratio of TCR/ECS) ranging from 0.4 to 0.8 , all of which are consistent with the evidence provided by the recent climate record and current modelling studies. It is immediately evident that, once TCR is specified, warming by any given date or cumulative carbon budget under these scenarios is largely insensitive to ECS, but the converse is not true. TCR, not ECS, determines the climate response on these timescales and hence is a much more policy relevant metric of uncertainty in the climate system's response to radiative forcing.

Physically this can be understood by realizing that the ECS is a theoretical quantity representing the warming that would occur only if atmospheric concentrations of greenhouse gases were held constant indefinitely while the climate system was allowed to come into equilibrium. Such a 'constant radiative forcing' scenario would require a very precise low level of emission of $\mathrm{CO}_{2}$ sustained over many centuries to precisely compensate for ocean $\mathrm{CO}_{2}$ uptake. This is clearly not a particularly policyrelevant scenario. TCR (through its link to the TCRE) is a much more relevant characteristic of the climate response to radiative forcing for climate mitigation scenarios.

This is important because climate system response uncertainty is often specified in IAMs and other economic calculations solely in terms of uncertainty in ECS (USG, 2010; Marten, 2011), whereas it would make more sense (and be no more complicated) to specify this uncertainty in terms of TCR, as in the PAGE2009 model (Hope, 2013), or better still TCRE to also take into account the carbon-cycle response. In some applications of the FUND model (Narita et al., 2010), for example, response-time scales of the climate system are automatically adjusted in order to give a similar TCR as the ECS is varied (Marten, 2011), in which case it may be unclear how the TCR or TCRE has been sampled.

As Marten (2011) observes, this is not a criticism of the IAMs themselves, but a problem with the (still all too common) practice of representing climate response uncertainty solely in terms of a distribution on ECS. ECS has very little to recommend it as a parameter to characterize the climate response in integrated assessment calculations. It is poorly constrained by observations, subject to fat-tailed uncertainty (Roe and Baker, 2007; Weitzmann, 2009), and not a particularly effective predictor of either peak warming under temperature-stabilization scenarios or the social cost of carbon. Fortunately, simple and more appropriate alternatives exist in TCR and TCRE.

Both TCR and TCRE are much better constrained by observations than ECS because, while we have no direct observations of the equilibrium response of the climate system to anything, we have observed the response to a gradual increase in radiative forcing (for TCR), or a slow injection of $\mathrm{CO}_{2}$ (for TCRE), over the past 150 years or so. Hence the IPCC was able to rule out a value of TCR greater than $3^{\circ} \mathrm{C}$ as extremely unlikely (less than 5 per cent chance) because the combination of warming observed to date and past radiative forcing is simply inconsistent with such a high value. The same argument applies to TCRE, and the only reason the IPCC did not give a similar extremely unlikely upper bound on TCRE was that this quantity had been less widely 
scrutinized in the peer-reviewed literature. In contrast, no such definitive statement could be given regarding an upper bound on ECS despite over 30 years of intense scrutiny, because it is impossible to exclude a substantial additional warming after atmospheric composition stabilizes on the basis of changes observed or modelling studies performed to date, particularly if atmospheric feedbacks change as the climate system converges towards a new equilibrium state, as they do in full-complexity climate models (Held et al., 2010).

TCRE is the most parsimonious parameter to represent global carbon cycle and climate response uncertainty in IAMs. It can be evaluated from any plot of $\mathrm{CO}_{2}$ induced warming against cumulative carbon emissions, such as Figure 1(c). A minimum requirement for integrated assessment calculations that purport to address climate response uncertainty should be to produce such a plot and demonstrate that the TCRE values used span the currently accepted range.

Characterizing the climate response in terms of TCRE instead of some combination of ECS, climate response timescales, and carbon cycle response is a rare example of how including additional feedbacks into the representation of the climate system actually simplifies its end-to-end behaviour. This is nicely exemplified by a recent study by Ricke and Caldeira (2014). In that study, the authors combine simple carbon-cycle models and a simple thermal climate model (representing the response to radiative forcing) obtained by separate fits to simulations of complex Earth System Models. These combinations can fail to account for the feedbacks between the carbon cycle and temperature response over time, as simulated by more complex models. They find, when they use their carbon-cycle models to drive their thermal climate models, the temperature response to a instantaneous pulse emission of $\mathrm{CO}_{2}$ (a fundamental determinant of the social cost of carbon) is typically represented by an initial temperature increase and subsequent decline over the century following the injection, unlike in more comprehensive models where the temperature stays roughly constant for over a century (see Figure 4 of Joos et al. (2013)). Accounting for these feedbacks within simple carbon-cycle-climate models is essential for capturing the IPCC's finding that temperatures are, on these multi-decade timescales, largely determined by cumulative emissions of $\mathrm{CO}_{2}$, independent of when those emissions occur.

\section{The role of non- $\mathrm{CO}_{2}$ gases on carbon budgets}

The previous section discussed uncertainty in the TCRE and its constituents and the most useful summary metrics of the climate response to $\mathrm{CO}_{2}$ emissions. However, as noted in the introduction, the other key factor in understanding uncertainty in carbon budgets is assumptions about other non- $\mathrm{CO}_{2}$ contributions to future anthropogenic warming, such as methane emissions or sulphate aerosol emissions (which have a cooling effect on the global climate). These assumptions regarding non- $\mathrm{CO}_{2}$ drivers are significant: the IPCC's estimate for the budget for remaining emissions to limit $\mathrm{CO}_{2}$-induced warming alone to $2^{\circ} \mathrm{C}$ is almost double the corresponding budget to limit total anthropogenic warming to $2^{\circ} \mathrm{C}(275 \mathrm{GtC}$ versus $485 \mathrm{GtC})$. In this section, we consider the impact of these non- $\mathrm{CO}_{2}$ climate drivers on various estimates of the carbon budget consistent with $2^{\circ} \mathrm{C}$. 
Figure 5, reproduced from Figure SPM10 of Stocker et al. (2013), demonstrates these points by placing a number of cumulative carbon budgets that have been proposed as relevant to the $2{ }^{\circ} \mathrm{C}$ goal into the context of the evidence considered by the IPCC. The coloured lines and shaded regions show the average response of the CMIP5 coupled models to the four RCP scenarios previously shown in Figure 2, while the shaded plume shows the inter-model range for the response under all four RCP scenarios. As in Figure $1(d)$, we see a straight line, scenario-independent relationship between total human-induced warming and cumulative carbon emissions. The solid black line shows the multi-model average response to cumulative $\mathrm{CO}_{2}$ emissions in runs driven only with increasing $\mathrm{CO}_{2}$. Non- $\mathrm{CO}_{2}$ climate drivers add up to $0.5^{\circ} \mathrm{C}$ to $\mathrm{CO}_{2}$-induced warming by the time cumulative $\mathrm{CO}_{2}$ emissions reach $1,000 \mathrm{GtC}$ in all scenarios, and over $1^{\circ} \mathrm{C}$ by the end of the century in the RCP8.5 scenarios. More generally, mitigation scenarios project a non- $\mathrm{CO}_{2}$ warming at the time of zero $\mathrm{CO}_{2}$ emissions of about $0.4-0.6^{\circ} \mathrm{C}$ (Rogelj et al., in press).

This figure supports a range of potential ' $2{ }^{\circ} \mathrm{C}$ carbon budgets' depending on the acceptable level of risk, in the light of current knowledge, of temperatures exceeding $2{ }^{\circ} \mathrm{C}$ and assumptions regarding non- $\mathrm{CO}_{2}$ climate drivers. The crosses show some illustrative cases. At the one extreme, the left-most cross indicates that limiting cumulative emissions to an overall budget of around $700 \mathrm{GtC}$ would give a high chance of temperatures remaining below $2^{\circ} \mathrm{C}$ even if warming due to non- $\mathrm{CO}_{2}$ drivers were over $0.5^{\circ} \mathrm{C}$ at the time temperatures peak. This would correspond approximately to a budget similar to that proposed by Meinshausen et al. (2009) giving a 25 per cent chance of temperatures exceeding $2^{\circ} \mathrm{C}$. A budget of about $800 \mathrm{GtC}$ would give a 33 per cent chance of temperatures exceeding $2^{\circ} \mathrm{C}$ with typical assumptions regarding non- $\mathrm{CO}_{2}$ climate drivers: this approximately corresponds to the IPCC's $1,000 \mathrm{GtCO}_{2}$ from 2011 case (middle cross).

Having emphasized the linear relationship between cumulative carbon emissions and warming, it may seem pessimistic to suggest that there is such a high chance of a warming of over a degree accompanying cumulative emissions of the next 200-300 $\mathrm{GtC}$ given they have only increased by just under a degree in response to, among other factors, the last $515 \mathrm{GtC}$. In 2011, total human-induced warming relative to mid-nineteenth century (a reasonable proxy for pre-industrial) conditions was about $0.9^{\circ} \mathrm{C}$ (Otto et al., 2015). But net forcing due to non- $\mathrm{CO}_{2}$ climate drivers (about 20 per cent of the total in 2011 according to Myhre et al. (2013)) is expected to increase in the future both in baseline and mitigation scenarios. The reason is that emissions of some other greenhouse gases will continue (being linked to food production, for example) and may even increase as a consequence of mitigation policies (for example, higher $\mathrm{N}_{2} \mathrm{O}$ emissions due to increased fertilizer use for biomass production for energy). Also, while the transition from coal to gas would remove fugitive methane emissions from coal extraction, it may also result in higher emissions in the short term due to methane venting and leakage. Finally, air pollution measures are being put into place to reduce emissions of aerosols and aerosol precursors because of their highly negative effects on regional environment and human health. Given that aerosols and aerosol precursors currently have an overall cooling effect (Myhre et al., 2013), removing them in equal proportions would lead to an overall positive forcing.

Projections of future non- $\mathrm{CO}_{2}$ climate drivers depend on many socio-economic and policy considerations. Arguments have been made (e.g. Shindell et al., 2012) that 
policies specifically targeting methane and black carbon (soot) emissions could reduce non- $\mathrm{CO}_{2}$-induced warming by up to $0.5^{\circ} \mathrm{C}$ by mid-century, which would largely offset the projected increase in non- $\mathrm{CO}_{2}$-induced warming under standard baseline and mitigation scenarios. However, more recent research has shown that this is an important overestimate (Rogelj et al., 2014a) when accounting for the linkages between the sources of non- $\mathrm{CO}_{2}$ climate drivers and fossil fuel combustion sources. It also remains contested whether these policies which only focus on methane and black carbon are achievable in the real world, as they assume absolutely no action on cooling aerosols, like sulphur dioxide (Rogelj et al., 2014a).

Conversely, if non- $\mathrm{CO}_{2}$ warming can be significantly reduced, then the carbon budget for $2^{\circ} \mathrm{C}$ would be substantially increased (Rogelj et al., in press). If, for example, the ratio of net non- $\mathrm{CO}_{2}$ to $\mathrm{CO}_{2}$ forcing could be kept to today's level even as $\mathrm{CO}_{2}$ forcing is stabilized, then cumulative emissions of $1,000 \mathrm{GtC}\left(1,800 \mathrm{GtCO}_{2}\right.$ after 2011) would give approximately even odds of temperatures exceeding $2^{\circ} \mathrm{C}$ (right cross). It is important to stress that this non- $\mathrm{CO}_{2}$ to $\mathrm{CO}_{2}$ forcing ratio rises in almost all mitigation scenarios for the reasons mentioned above and despite IAMs having explored current possibilities for mitigation of non- $\mathrm{CO}_{2}$-induced warming. New mitigation breakthroughs in this area would impact the available carbon budget (Rogelj et al., 2015a). Net non- $\mathrm{CO}_{2}$ forcing is unlikely to become strongly negative except in the case of specific geo-engineering scenarios to reduce incoming solar radiation and for many sources of non- $\mathrm{CO}_{2}$ climate drivers linked to food production no compelling mitigation technologies are available at this point (Smith et al., 2014). So the assumption that the ratio of net non- $\mathrm{CO}_{2}$ to $\mathrm{CO}_{2}$ forcing could be kept to today's level probably represents the most (if not overly) optimistic budget that is consistent with $2^{\circ} \mathrm{C}$, given the evidence available today.

Given the importance of non- $\mathrm{CO}_{2}$ climate drivers in determining the cumulative carbon budget consistent with any particular temperature goal, it may be tempting to combine all climate drivers into a single 'cumulative $\mathrm{CO}_{2}$-equivalent budget' Tempting but wrong. Short-lived climate pollutants such as methane and aerosols do not accumulate in the atmosphere as $\mathrm{CO}_{2}$ does. Their contribution to peak warming depends on emission rates around the time of peak warming, not on cumulative emissions up to that time (Smith et al., 2012). Also, because of their much shorter lifetime in the atmosphere, their emission up to a given time is not indicative of any long-term warming. Hence there is no alternative to keeping track separately of the expected warming from non- $\mathrm{CO}_{2}$ drivers and computing a cumulative $\mathrm{CO}_{2}$ budget consistent with the remainder. Earlier studies have done so (Meinshausen et al., 2009) and accounted separately for $\mathrm{CO}_{2}$ and non- $\mathrm{CO}_{2}$ climate drivers in their climate simulations. Based on informed assumptions of how $\mathrm{CO}_{2}$ paths can be complemented with consistent evolutions of non- $\mathrm{CO}_{2}$ climate drivers (Meinshausen, 2007; Rogelj et al., 2014b), $\mathrm{CO}_{2}$-equivalent budgets can be calculated, but these only provide an ex post characterization of emissions scenarios, not a geophysical constraint.

Hence budgets for future $\mathrm{CO}_{2}$ emissions consistent at some level with meeting the $2{ }^{\circ} \mathrm{C}$ limit, range over a factor of two or more. Some of this range arises from uncertainty in the TCRE (as discussed in section III), which can be dealt with in principle if agreement could be secured on what level of risk we are prepared to accept of temperatures exceeding $2^{\circ} \mathrm{C}$. But a substantial contribution to the range arises from uncertainty in how much warming will need to be 'reserved' for non- $\mathrm{CO}_{2}$ 
climate drivers. This is more contestable, since there is a wide range of views and significant uncertainty on the potential for non- $\mathrm{CO}_{2}$ climate mitigation.

\section{A way out of uncertainty: adaptive policies targeting 'net zero by $2{ }^{\circ} \mathrm{C}$ '}

The uncertainties in choosing a cumulative carbon budget, as highlighted by the previous sections may seem so large as to call into question whether this concept can be useful for policy at all. In this section, we argue that acknowledging the existence of a cumulative carbon budget, even if its size is uncertain, can have a substantial impact on mitigation policy, and that the right way to deal with uncertainty in the carbon budget is to design policies that can adapt to the evolving signal of humaninduced climate change.

On a practical level, the effectively permanent influence of carbon emissions on global temperatures provides a useful simplification for many economic questions. Because of the cancellation of non-linearities coming from carbon-cycle feedbacks and from the logarithmic relationship between concentrations and radiative forcing of $\mathrm{CO}_{2}$ (see section II), the response to a pulse injection of $\mathrm{CO}_{2}$ can be very simply characterized by a rapid warming set by the size of the injection and the TCRE followed by essentially constant temperatures for roughly a century or more (Joos et al., 2013). This has the potential to significantly simplify calculations of quantities such as the social cost of carbon, and also simplifies the problem of assigning responsibility for warming (Matthews, 2015), within limits (Fuglestvedt and Kallbekken, 2015).

On a more general policy level, regardless of the actual size of the carbon budget for a specific warming threshold, to stabilize global temperatures without active geoengineering measures, net global $\mathrm{CO}_{2}$ emissions will need to be reduced to zero. Hence nations, sectors, or companies that are committed to stabilizing temperatures at $2{ }^{\circ} \mathrm{C}$, or any other target temperature, are implicitly committed to reducing net $\mathrm{CO}_{2}$ emissions from their activities to zero by the time human-induced warming reaches that target temperature (or to explain how some other entity is going to compensate for their residual emissions by active $\mathrm{CO}_{2}$ removal measures).

The size of net human-induced warming at present, although not known with exact certainty, is less uncertain than the TCRE. ${ }^{8}$ It is also much less uncertain than past or projected future warming due to non- $\mathrm{CO}_{2}$ climate drivers. Human-induced warming is inferred from a statistical comparison of the historical temperature record with the expected responses to anthropogenic and natural forcing, and is largely independent of the details of the models or method used to calculate it. Hence we can state with a high level of confidence that net human-induced warming currently stands at just over $0.9^{\circ} \mathrm{C}$ and increased by about $0.1^{\circ} \mathrm{C}$ between 2009 and 2015 (Otto et al., 2015).

\footnotetext{
${ }^{8}$ The reason for this is that cancellation of errors means that net warming from all anthropogenic drivers is better constrained by observations than warming attributable to $\mathrm{CO}_{2}$ alone (Bindoff et al., 2013).
} 
Under the new 'pledge and review' approach to mitigation policy in the UNFCCC, an up-to-date real-time index of human-induced warming could provide a way of dealing with uncertainty in the cumulative carbon budget while framing policies that are clearly targeted at meeting the $2^{\circ} \mathrm{C}$ goal. Human-induced warming is already approaching $1^{\circ} \mathrm{C}$. If temperatures are to be stabilized at $2^{\circ} \mathrm{C}$ (without active geoengineering), then $\mathrm{CO}_{2}$ emissions need to be reduced and reach net zero at the time when global temperatures reach $2^{\circ} \mathrm{C}$. This is not a statement of policy, but a simple fact that follows from the longevity of carbon. For this to occur, this requires an on average 10 per cent reduction (relative to today's levels) in global net $\mathrm{CO}_{2}$ emissions for every tenth of a degree of additional human-induced warming. The advantage of such an explicitly adaptive approach is that new knowledge about the climate response could be quickly and directly incorporated into mitigation polices, removing the need to estimate the exact size of the remaining carbon budget at any point in time.

Parties to the UNFCCC have considerable flexibility in how to frame their 'pledges' (or 'nationally determined contributions', as they have been named under the Paris Agreement), and at present are allowed to adopt their own metrics to measure progress in greenhouse gas reductions. Metrics are generally understood in this context to mean how reductions in different greenhouse gases are aggregated to give an overall percentage reduction. The possibility of including attributable warming in the metric used to measure greenhouse gas reductions has not, to our knowledge, been suggested, but it would be possible in principle. To amend the process of bottom-up country pledges, a process of regular stocktakings has been put in place under the UNFCCC (UNFCCC, 2015). Such stocktakings shall consider the aggregate progress of the efforts by parties towards avoiding dangerous anthropogenic climate change, as well as assessments of the best available science. Including attributable warming as a metric in these stocktakings would provide a much more transparent link between, and continuous reminder of, the implications of near-term policies and the overall goal of achieving net zero $\mathrm{CO}_{2}$ emissions by the time the $2^{\circ} \mathrm{C}$ limit is reached. This approach helps to avoid the need to resolve the uncertainties in the remaining cumulative carbon budget, without losing a clear link to the geophysical reality.

\section{Conclusion}

The notion of an all-time carbon budget has quickly become established in climate policy discussions as a useful way to analyse the impacts of mitigation policies. This development has been welcome, as it reflects a correct focus on a variable that physically determines climate impacts, as opposed to a focus on emissions flows in the atmosphere in a given year (section II). However, the simplicity of boiling down the climate response to a single number associated with a certain warming target masks several more complex issues that create uncertainty in the carbon budget for particular warming thresholds.

In this article, we have discussed these sources of uncertainty and their relevance to climate policy. In particular, we have focused on the uncertainty arising from inherent uncertainty in the transient response of the climate system to cumulative emissions 
(TCRE) itself and recommend that economic and integrated assessment analyses sample uncertainty in climate parameters (such as the transient climate responseTCR) that are directly linked to uncertainty in the policy-relevant TCRE (section III). This is in contrast to the current misconception that sampling the equilibrium climate sensitivity (a climate parameter not strongly linked to the TCRE) is sufficient to capture policy-relevant uncertainty in the physical climate system. Understanding assumptions regarding uncertain future non- $\mathrm{CO}_{2}$ climate forcing agents is also essential to understand the implications of future mitigation actions when using a specified carbon budget (section IV).

To deal with these uncertainties we have proposed a new form of climate policy, which could allow uncertainty in the exact size of the carbon budget to be circumvented (section V). By indexing climate policies against evolving anthropogenic warming to ensure net zero emissions of $\mathrm{CO}_{2}$ are reached at the time at which temperatures reach a specified warming target, a property of the physical climate system can be exploited to ensure that long-lived warming will not exceed this threshold independent of uncertainties in the climate response and the role of non$\mathrm{CO}_{2}$ climate drivers.

In December 2015, the world governments committed to limiting warming to 'well below' $2^{\circ} \mathrm{C}$ with the ambition to limit it to only $1.5^{\circ} \mathrm{C}$ (UNFCCC, 2015). Understanding many of the issues raised in this article will be essential for accurately assessing the implications of these goals for climate mitigation actions over the coming decade. Scaling down IPCC-AR5 carbon budgets to assess $1.5^{\circ} \mathrm{C}$ budgets, in order to limit overall human-induced warming to $1.5^{\circ} \mathrm{C}$ with $>66$ per cent probability, our remaining carbon budget could almost already be exhausted today. Likewise, if we assume $0.5^{\circ} \mathrm{C}$ warming due to non- $\mathrm{CO}_{2}$ drivers is inescapable, then the cumulative $1.5^{\circ} \mathrm{C}$ carbon budget is nearly exhausted already. Indeed, energy-economic studies have at present only found ways to limit warming to below $1.5^{\circ} \mathrm{C}$ after temporarily exceeding that limit (Rogelj et al., 2015b). But there may be more flexibility in future non- $\mathrm{CO}_{2}$ warming than current scenarios suggest, although this is clearly a question that requires further research. Hence, as the current anthropogenic warming stands at about $0.9^{\circ} \mathrm{C}$, it is likely (save for the small chance of a very large aerosol cooling masking warming in the current climate) that we are not quite as close to committing to overall $1.5^{\circ} \mathrm{C}$ warming as a very simplified analysis of the carbon budget might imply. Understanding the implications of the emerging climate response, as well as exploring future assumptions regarding non- $\mathrm{CO}_{2}$ climate forcing will be essential in assessing mitigations polices that aim to put the UNFCCC goals into action. 


\section{References}

350.org (2012), 'Do The Math', accessed at http://math.350.org

Allen, M. R., et al. (2009), 'Warming Caused by Cumulative Carbon Emissions Towards the Trillionth Tonne', Nature, 458(7242), 1163-6.

Archer, D. (2005), 'Fate of Fossil Fuel $\mathrm{CO}_{2}$ in Geologic Time', Journal of Geophysical Research: Oceans (1978-2012), 110(C9).

Archer, D., and Brovkin, V. (2008), 'The Millennial Atmospheric Lifetime of Anthropogenic CO2', Climatic Change, 90(3), 283-297.

Bindoff, N. L., et al. (2013), 'Detection and Attribution of Climate Change: from Global to Regional', in T. Stocker et al. (eds), Climate Change 2013: The Physical Science Basis. Contribution of Working Group I to the Fifth Assessment Report of the Intergovernmental Panel on Climate Change, Cambridge, Cambridge University Press.

Boucher, O., and Reddy, M. S. (2008), 'Climate Trade-off between Black Carbon and Carbon Dioxide Emissions', Energy Policy, 36(1), 193-200.

Bruckner, T., et al. (2014), 'Energy Systems', in O. Edenhofer et al. (eds), Climate Change 2014: Mitigation of Climate Change. Contribution of Working Group III to the Fifth Assessment Report of the Intergovernmental Panel on Climate Change, Cambridge, Cambridge University Press.

Ciais, P., et al. (2013), 'Attributing the Increase in Atmospheric CO2 to Emitters and Absorbers', Nature Climate Change, 3(10), 926-30.

Clarke, L., et al., (2014), 'Assessing Transformation Pathways', in T. Stocker et al. (eds), Climate Change 2014: Mitigation of Climate Change. Contribution of Working Group III to the Fifth Assessment Report of the Intergovernmental Panel on Climate Change, Cambridge, Cambridge University Press.

Carbon Tracker Initiative (2011), 'Unburnable Carbon', accessed at http://www.carbontracker.org/report/carbon-bubble/

Collins, M. et al. (2013), 'Long-term Climate Change: Projections, Commitments and Irreversibility', in T. Stocker et al. (eds), Climate Change 2013: The Physical Science Basis. Contribution of Working Group I to the Fifth Assessment Report of the Intergovernmental Panel on Climate Change, Cambridge, Cambridge University Press.

Edenhofer, O. et al. (2014), 'Summary for Policymakers', in O. Edenhofer et al. (eds), Climate Change 2014: Mitigation of Climate Change. Contribution of Working Group III to the Fifth Assessment Report of the Intergovernmental Panel on Climate Change, Cambridge, Cambridge University Press. 
Field, C., et al. (2014), 'Summary for Policymakers', in C. Field et al. (eds), Climate Change 2014: Impacts, Adaptation and Vulnerability. Part A: Global and Sectoral Aspects. Contribution of Working Group II to the Fifth Assessment Report of the Intergovernmental Panel on Climate Change, Cambridge, Cambridge University Press.

Frame, D. J., et al. (2006), 'Alternatives to Stabilization Scenarios', Geophysical Research Letters, 33(14).

Friedlingstein, P., et al. (2006), 'Climate-carbon Cycle Feedback Analysis: Results from the C4MIP Model Intercomparison', Journal of Climate, 19(14), 333753.

Friedlingstein, P., et al. (2014), 'Persistent Growth of $\mathrm{CO}_{2}$ Emissions and Implications for Reaching Climate Targets', Nature Geoscience, 7(10), 70915.

Fuglestvedt, J. S., and Kallbekken, S. (2015), 'Climate Responsibility: Fair Shares?', Nature Climate Change, 6(1), 19-20.

Gillett, N. P., et al. (2013), 'Constraining the Ratio of Global Warming to Cumulative $\mathrm{CO}_{2}$ Emissions Using CMIP5 Simulations', Journal of Climate, 26(18), 684458.

Gloor, M., Sarmiento, J. L., and Gruber, N. (2010), 'What Can Be Learned About Carbon Cycle Climate Feedbacks from the $\mathrm{CO}_{2}$ Airborne Fraction?', Atmospheric Chemistry and Physics, 10(16), 7739-51.

Held, I. M., et al. (2010), 'Probing the Fast and Slow Components of Global Warming by Returning Abruptly to Preindustrial Forcing', Journal of Climate, 23(9), $2418-27$.

Hope, C. (2013), 'Critical Issues for the Calculation of the Social Cost of $\mathrm{CO}_{2}$ : Why the Estimates from PAGE09 are Higher than those from PAGE2002', Climatic Change, 117, 531-43.

Joos, F., et al., (2013), 'Carbon Dioxide and Climate Impulse Response Functions for the Computation of Greenhouse Gas Metrics: A Multi-Model Analysis', Atmospheric Chemistry and Physics, 13(5), 2793-825.

Knorr, W. (2009), 'Is the Airborne Fraction of Anthropogenic $\mathrm{CO}_{2}$ Emissions Increasing?', Geophysical Research Letters, 36(21).

Knutti, R., and Rogelj, J. (2015), 'The Legacy of our $\mathrm{CO}_{2}$ Emissions: A Clash of Scientific Facts, Politics and Ethics', Climatic Change, 1-13.

Kriegler, E., et al. (2013), 'Is Atmospheric Carbon Dioxide Removal a Game Changer for Climate Change Mitigation?', Climatic Change, 118(1), 45-57. 
McGlade, C., and Ekins, P. (2015), 'The Geographical Distribution of Fossil Fuels Unused When Limiting Global Warming to $2^{\circ} \mathrm{C}^{\prime}$, Nature, 517(7533), 187-90.

Marten, A. L. (2011), 'Transient Temperature Response Modeling in IAMs: The Effects of Over Simplification on the SCC', Economics: The Open-Access, Open-Assessment E-Journal, 5.

Matthews, H. D. (2015), 'Quantifying Historical Carbon and Climate Debts Among Nations', Nature Climate Change, doi:10.1038/nclimate2774.

Matthews, H. D., and Caldeira, K. (2008), 'Stabilizing Climate Requires Near-zero Emissions', Geophysical Research Letters, 35(4).

Matthews, H. D., et al. (2009), 'The Proportionality of Global Warming to Cumulative Carbon Emissions', Nature, 459(7248), 829-32.

Meinshausen, M. (2007), 'Stylized Emission Path', No. HDOCPA-2007-51, Human Development Report Office (HDRO), United Nations Development Programme (UNDP).

Meinshausen, M., et al. (2009), 'Greenhouse-gas Emission Targets for Limiting Global Warming to $2^{\circ} \mathrm{C}$ ', Nature, 458(7242), 1158-62.

Meinshausen, M., Raper, S. C. B., and Wigley, T. M. L. (2011), 'Emulating Coupled Atmosphere-Ocean and Carbon Cycle Models with a Simpler Model, MAGICC6-Part 1: Model Description and Calibration', Atmospheric Chemistry and Physics, 11(4), 1417-56.

Millar, R. J., et al. (2015), 'Model Structure in Observational Constraints on Transient Climate Response', Climatic Change, 1-13.

Myhre, G., et al., (2013), 'Anthropogenic and Natural Radiative Forcing', in T. Stocker et al. (eds), Climate Change 2013: The Physical Science Basis. Contribution of Working Group I to the Fifth Assessment Report of the Intergovernmental Panel on Climate Change, Cambridge, Cambridge University Press.

Narita, D., Tol, R. S. J., and Anthoff, D. (2010), 'Economic Costs of Extratropical Storms under Climate Change: An Application of FUND', Journal of Environmental Planning and Management, 53(3), 371-84.

Nordhaus, W., and Sztorc, P. (2013), DICE2013R: Introduction and Users Manual, 2nd edn, October.

Otto, A., et al. (2013), 'Energy Budget Constraints on Climate Response', Nature Geoscience, 6(6), 415-16.

Otto, F. E. L., et al. (2015), 'Embracing Uncertainty in Climate Change Policy', Nature Climate Change, 5, 917-20. 
Pachauri, R. K., et al. (2014), 'Climate Change 2014: Synthesis Report', Contribution of Working Groups I, II and III to the Fifth Assessment Report of the Intergovernmental Panel on Climate Change (core writing team, R. K. Pachauri and L. A. Meyer (eds)), IPCC, Geneva.

Raupach, M. R., Canadell, J. G., and Le Quéré, C. (2008), 'Anthropogenic and Biophysical Contributions to Increasing Atmospheric $\mathrm{CO}_{2}$ Growth Rate and Airborne Fraction', Biogeosciences, 5(6), 1601-13.

Riahi, K., et al. (2011), 'RCP 8.5-A Scenario of Comparatively High Greenhouse Gas Emissions', Climatic Change, 109(1-2), 33-57.

Ricke, K. L., and Caldeira, K. (2014), 'Maximum Warming Occurs About One Decade after a Carbon Dioxide Emission', Environmental Research Letters, 9(12), 124002.

Rockström, J., et al. (2009), 'A Safe Operating Space for Humanity', Nature, 461(7263), 472-5.

Roe, G. H., and Baker, M. B. (2007), 'Why is Climate Sensitivity so Unpredictable?' Science, 318(5850), 629-32.

Rogelj, J., Meinshausen, M., and Knutti, R. (2012), 'Global Warming Under Old and New Scenarios Using IPCC Climate Sensitivity Range Estimates', Nature Climate Change, 2(4), 248-53.

Rogelj, J., et al. (2014a), 'Disentangling the Effects of $\mathrm{CO}_{2}$ and Short-lived Climate Forcer Mitigation', Proceedings of the National Academy of Sciences, 111(46), 16325-30.

Rogelj, J., et al. (2014b), 'Air-pollution Emission Ranges Consistent with the Representative Concentration Pathways', Nature Climate Change, 4(6), 44650 .

Rogelj, J., et al. (2015a), 'Impact of Short-lived non-CO $\mathrm{CO}_{2}$ Mitigation on Carbon Budgets for Stabilizing Global Warming', Environmental Research Letters, 10(7), 075001.

Rogelj, J., et al. (2015b), 'Energy System Transformations for Limiting End-ofcentury Warming to Below $1.5^{\circ} \mathrm{C}^{\prime}$, Nature Climate Change, 5(6), 519-27.

Rogelj, J., et al. (in press), 'Differences between Carbon Budget Estimates Unraveled', Nature Climate Change.

Scott, V., et al. (2015), 'Fossil Fuels in a Trillion Tonne World', Nature Climate Change, 5(5), 419-23.

Shindell, D., et al. (2012), 'Simultaneously Mitigation Near-term Climate Change and Improving Human Health and Food Security’, Science, 335, 183-9. 
Smith, P. et al. (2014), 'Agriculture, Forestry and Other Land Use (AFOLU)', in O. Edenhofer et al. (eds), Climate Change 2014: Mitigation of Climate Change. Contribution of Working Group III to the Fifth Assessment Report of the Intergovernmental Panel on Climate Change, Cambridge, Cambridge University Press.

Smith, S. M., et al. (2012), 'Equivalence of Greenhouse-gas Emissions for Peak Temperature Limits', Nature Climate Change, 2(7), 535-8.

Solomon, S., et al. (2009), 'Irreversible Climate Change due to Carbon Dioxide Emissions', Proceedings of the National Academy of Sciences, 106(6), 17049.

Stocker T., et al., (2013), 'Summary for Policymakers', in T. Stocker et al. (eds), Climate Change 2013: The Physical Science Basis. Contribution of Working Group I to the Fifth Assessment Report of the Intergovernmental Panel on Climate Change, Cambridge, Cambridge University Press.

Taylor, K. E., Stouffer, R. J., and Meehl, G. A. (2012), 'An Overview of CMIP5 and the Experiment Design', Bulletin of the American Meteorological Society, 93(4), 485-98.

Tol, R. S. J. (2009), 'The Economic Effects of Climate Change', Journal of Economic Perspectives, 29-51.

UNFCCC (2015), 'Paris Agreement', UN Framework Convention on Climate Change, accessed at https://unfccc.int/resource/docs/2015/cop21/eng/109r01.pdf

USG (2010), 'Technical Support Document: Social Cost of Carbon for Regulatory

Impact Analysis under Executive Order 12866', Interagency Working Group on Social Cost of Carbon, United States Government.

Van Vuuren, D. P., et al. (2011), 'The Representative Concentration Pathways: An Overview', Climatic Change, 109, 5-31.

Weitzman, M. L. (2009) 'On Modeling and Interpreting the Economics Oof Catastrophic Climate Change', =Review of Economics and Statistics, 91(1), 119.

Zickfeld, K., et al. (2009), 'Setting Cumulative Emissions Targets to Reduce the Risk of Dangerous Climate Change', Proceedings of the National Academy of Sciences, 106(38), 16129-34. 
Figure 1: The climate response to a broad range of emissions scenarios, demonstrating the importance of the cumulative carbon budget
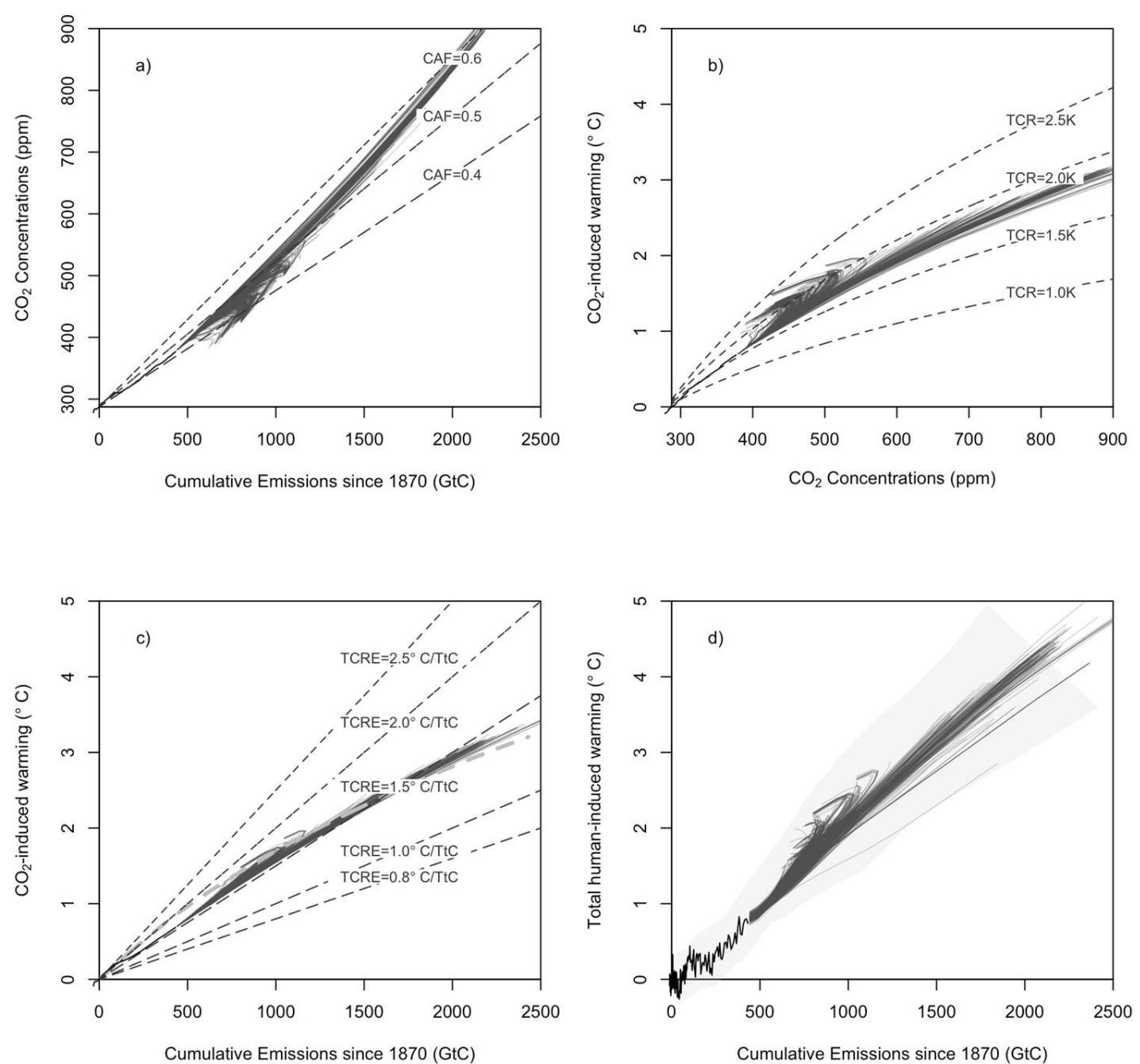

Notes: Red lines show the response of a simple climate model to 524 emission scenarios in the IPCC WG3 database, ranging from 'baseline' to stringent mitigation scenarios. Panels $(a)$ and $(b)$ show the convex relationship between $\mathrm{CO}_{2}$ concentrations and cumulative $\mathrm{CO}_{2}$ emissions and the concave relationship between $\mathrm{CO}_{2}$-induced warming and concentrations. These cancel to yield a near-straight relationship between $\mathrm{CO}_{2}$-induced warming and cumulative $\mathrm{CO}_{2}$ emissions in panel $(c)$. The dashed grey line in panel (c) shows the relationship under the assumption that the relationship shown in panel $(a)$ is perfectly linear. The relationship between total human-induced warming and $\mathrm{CO}_{2}$ emissions in panel $(d)$ shows more spread, but still an approximately straight-line scenario-independent behaviour. 


\section{Figure 2:}
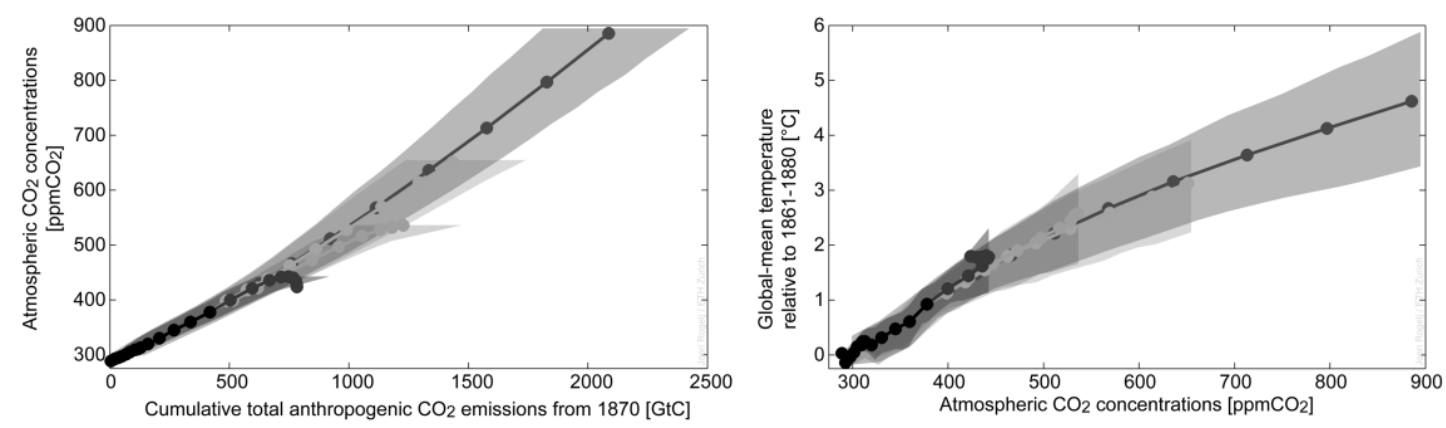

Notes: The figure shows the relationship between atmospheric $\mathrm{CO}_{2}$ concentrations and cumulative $\mathrm{CO}_{2}$ emissions (left panel) and total human-induced warming versus concentrations (right panel) in the CMIP5 ensemble of coupled Earth System Models in response to the four RCP scenarios, with plumes shows 5-95 per cent inter-model ranges.

Figure 3:
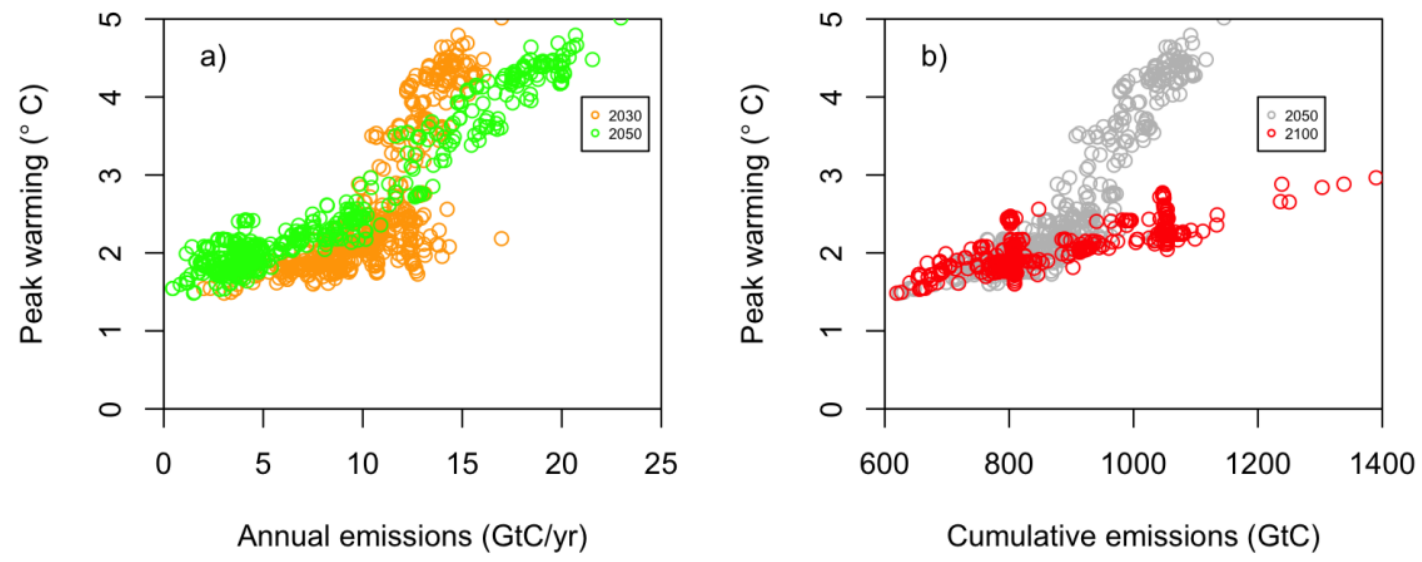

Notes: The figure shows peak warming or (in the case of scenarios that fail to stabilize) warming in 2100 in the IPCC WG3 scenarios plotted against $(a)$ emission rates in 2030 and 2050 and $(b)$ cumulative emissions to 2050 and 2100. 
Figure 4: Identifying climate system properties that determine the cumulative carbon budget
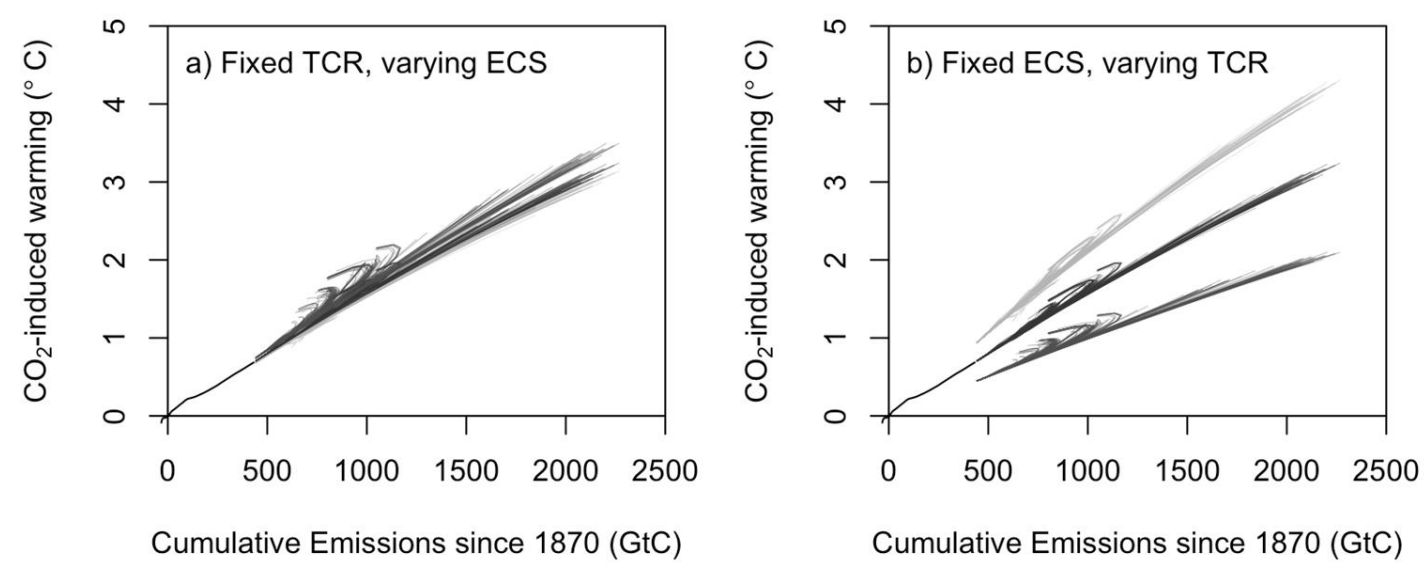

Notes: Panel (a) shows that when TCR is specified, varying ECS has little impact, whereas panel $(b)$ shows that even with ECS specified, the warming for a given cumulative $\mathrm{CO}_{2}$ emission is uncertain to within a factor of 2 . 
Figure 5: Total human-induced warming (coloured lines and pink plume) and $\mathrm{CO}_{2}$ induced warming (grey line and plume) versus cumulative $\mathrm{CO}_{2}$ emissions in fullcomplexity Earth System Models of the CMIP5 ensemble

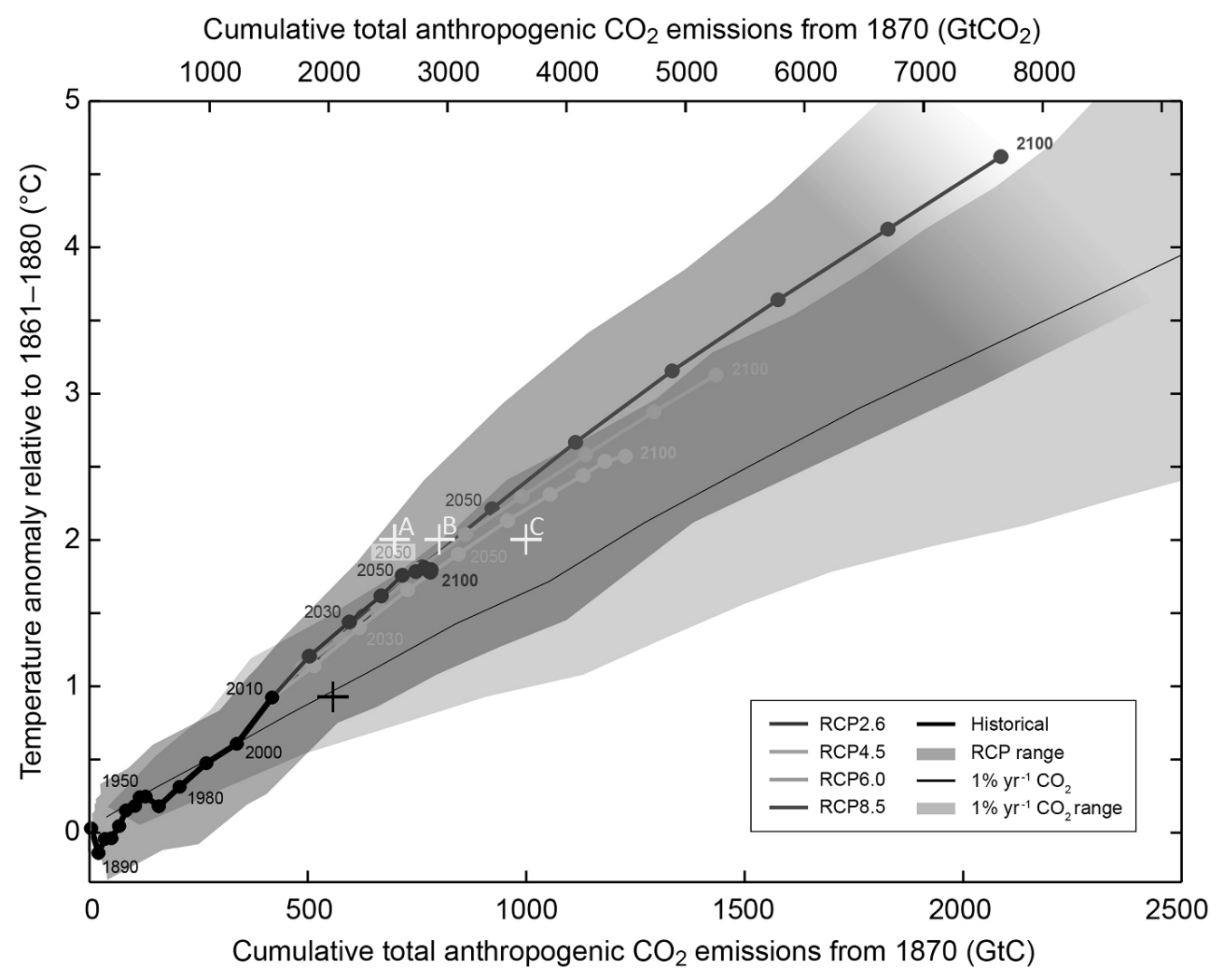

Notes: Coloured lines show response to four different scenarios, ranging from aggressive mitigation (RCP2.6) to business as usual (RCP8.5). Pink and grey plumes show 5-95 per cent range of uncertainty in response as a function of cumulative carbon emissions. Black cross shows estimated cumulative emissions and humaninduced warming in 2015 (Otto et al., 2015). Pale green crosses show cumulative carbon budgets associated with various levels of risk of temperatures exceeding $2^{\circ} \mathrm{C}$. Cross A shows $700 \mathrm{GtC}$, corresponding to the lower end of the budgets estimated using idealized climate models reported in Table 2.2 of IPCC (2014); cross B shows $800 \mathrm{GtC}$, corresponding to the IPCC's headline budget estimated to maintain warming below $2^{\circ} \mathrm{C}$ with $>66$ per cent probability; cross $\mathrm{C}$ shows $1,000 \mathrm{GtC}$, corresponding to $>66$ per cent probability of maintaining $\mathrm{CO}_{2}$-induced warming below $2{ }^{\circ} \mathrm{C}$, with the odds on total warming exceeding $2^{\circ} \mathrm{C}$ dependent on future non$\mathrm{CO}_{2}$ warming. 